\title{
Brønsted Acid Catalysed Aerobic Reduction of Olefins by Diimide Generated In Situ from Hydrazine
}

\author{
Yukihiro Arakawa ${ }^{a}$ (i) \\ Takahiro Kohda \\ Keiji Minagawab \\ Yasushi Imada*a (10) \\ a Department of Applied Chemistry, Tokushima University, \\ Minamijosanjima, Tokushima 770-8506, Japan \\ ${ }^{b}$ Institute of Liberal Arts and Sciences, Tokushima University, \\ Minamijosanjima, Tokushima 770-8502, Japan \\ imada@tokushima-u.ac.jp
}
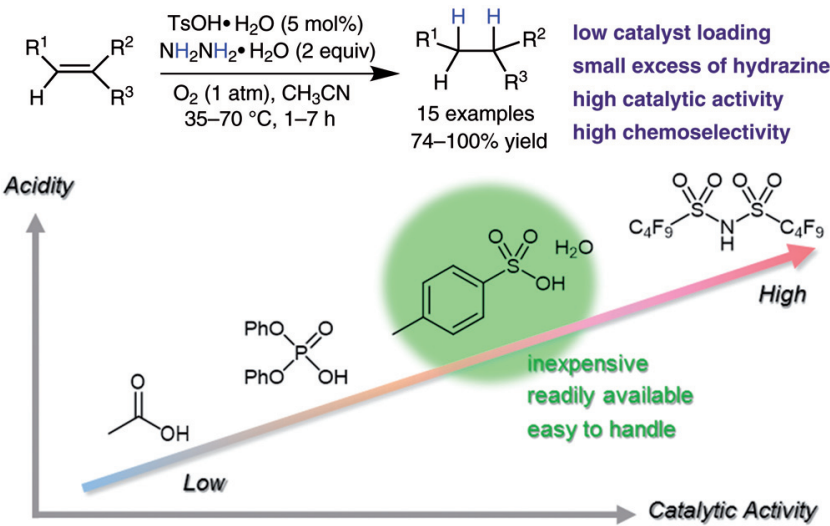

reaction times of $18-24 \mathrm{~h}$ (even under $1 \mathrm{~atm}$ of $\mathrm{O}_{2}$ ) were often required with $2-3$ equivalents of hydrazine. ${ }^{6}$ Guin et al. reported that the addition of a stoichiometric amount of arylboronate ester could accelerate reduction such that the reaction was complete within $1.5-8 \mathrm{~h}$ at $32{ }^{\circ} \mathrm{C}$ in acetonitrile with four equivalents of hydrazine; although stoichiometric amounts of phenol and boric acid were formed. ${ }^{7}$ We introduced synthetic flavins as efficient catalysts for the generation of diimide from hydrazine, which provided a convenient and safe process for the aerobic reduction of olefins, requiring as little as one equivalent of hydrazine. ${ }^{8}$ However, despite their versatility, expanded by ourselves ${ }^{8}$ and others, ${ }^{9}$ the $N 5$-alkylated flavin derivatives with highest activities are not commercially available and so this methodology has not been generally adopted in the laboratory or in industry. Kappe et al. utilised a gas-liquid continuous-flow system for diimide olefin reduction, which dramatically shortened reaction times to $10-30 \mathrm{~min}$ at $100{ }^{\circ} \mathrm{C}$ under 20 bar with 4-5 equivalents of hydrazine. ${ }^{10}$ Although such flow technologies are a useful and safe way of using highly labile diimide, ${ }^{10,11}$ they require special instrumentation that is still not common in research laboratories. As a result, the development of an efficient and readily available methodology for the aerobic reduction of olefins with hydrazine remains desirable.

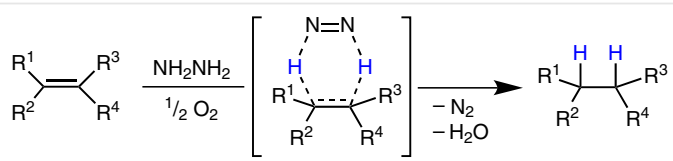

Scheme 1 Aerobic reduction of olefins with hydrazine

In the course of our research on the aerobic reduction of olefins with hydrazine, ${ }^{8}$ we examined an article published by Koch in 1968, in which the catalytic effect of acetic acid 
$(\mathrm{AcOH})$ for the aerobic reduction of methyl oleate with hydrazine in aprotic solvents such as acetonitrile and the kinetics of the process were presented. ${ }^{12}$ Although the role of $\mathrm{AcOH}$ was not fully rationalised in the original report, it was commented later by Pasto and Taylor in a review ${ }^{2 a}$ that AcOH could catalyse slow equilibration of unreactive transdiimide and reactive cis-diimide. Nevertheless, we were quite surprised that no other Brønsted acids have so far been explored as catalysts for the aerobic reduction of olefins with hydrazine.

Within this manuscript, the catalytic activities of a variety of Brønsted acids for the aerobic reduction of olefins with hydrazine are disclosed. We demonstrate that $p$-toluenesulfonic acid monohydrate $\left(\mathrm{TsOH} \cdot \mathrm{H}_{2} \mathrm{O}\right)$, one of the most common, inexpensive, and readily available organic acids, is particularly useful as a catalyst in terms of both reaction efficiency and availability, which allows a range of olefins to be reduced with high chemoselectivity under mild conditions.

Initially, several commercially available organic acids having different acidities, $\mathrm{AcOH}\left[\mathrm{p} K_{\mathrm{a}}=23.51\left(\mathrm{CH}_{3} \mathrm{CN}\right){ }^{13 \mathrm{a}}\right.$ $\left.4.76\left(\mathrm{H}_{2} \mathrm{O}\right)^{13 \mathrm{~b}}\right]$, diphenylphosphate [DPP, $\mathrm{p} K_{\mathrm{a}}=1.9\left(\mathrm{H}_{2} \mathrm{O}\right)^{13 \mathrm{c}}$ ], methanesulfonic acid [MsOH, $\left.K_{\mathrm{a}}=10.0\left(\mathrm{CH}_{3} \mathrm{CN}\right)^{13 \mathrm{~d}}\right]$, toluenesulfonic acid monohydrate $\left[\mathrm{TsOH} \cdot \mathrm{H}_{2} \mathrm{O}, \mathrm{p} K_{\mathrm{a}}=8.6\right.$ $\left.\left(\mathrm{CH}_{3} \mathrm{CN}\right)^{13 \mathrm{a}}\right]$, and bis $(1,1,2,2,3,3,4,4,4$-nonafluoro-1-butanesulfonyl)imide $\left[\left(\mathrm{C}_{4} \mathrm{~F}_{9} \mathrm{SO}_{2}\right)_{2} \mathrm{NH}, \mathrm{p} K_{\mathrm{a}}=0.0\left(\mathrm{CH}_{3} \mathrm{CN}\right)^{13 \mathrm{e}}\right]$, were explored for the aerobic reduction of 4-phenyl-1-butene (1a) to butylbenzene (2a). The reactions were carried out with $0.25 \mathrm{mmol}$ of $\mathbf{1 a}$ and 2 equivalents of hydrazine monohydrate $\left(\mathrm{NH}_{2} \mathrm{NH}_{2} \cdot \mathrm{H}_{2} \mathrm{O}\right)$ under 1 atm of $\mathrm{O}_{2}$ at $35^{\circ} \mathrm{C}$ in the presence of $5 \mathrm{~mol} \%$ of each acid in acetonitrile and the reaction was closely monitored by GC analysis for 60 minutes (Scheme 2). A control experiment showed that the reaction in the absence of any acids could proceed only very slowly to give $\mathbf{2 a}$ in $5 \%$ yield after 60 minutes. The catalytic behaviour of $\mathrm{AcOH}$, reported by Koch, ${ }^{12}$ was reproduced, resulting in 2a being obtained in $17 \%$ yield after the same reaction time. We anticipated that much stronger acids should promote the reaction more by rendering the equilibration of trans- and cis-diimide faster. As expected, DPP showed considerably higher catalytic activity compared with $\mathrm{AcOH}$, giving a yield of $50 \%$ in 1 hour. Remarkably, nearly quantitative yields were observed when $\mathrm{TsOH} \cdot \mathrm{H}_{2} \mathrm{O}$ or $\left(\mathrm{C}_{4} \mathrm{~F}_{9} \mathrm{SO}_{2}\right)_{2} \mathrm{NH}$ (even stronger acids than DPP) was used under the same conditions; while $\mathrm{MsOH}$ was unexpectedly sluggish. In this case, the reaction mixture became heterogeneous, with formation of a white precipitate that could be a hydrazonium salt of $\mathrm{MsOH}$, rendering the catalyst ineffective. To evaluate the catalytic activity of each Brønsted acid more precisely, the ratios $\left(k_{\mathrm{obs}} / k_{0}\right)$ of the initial rate of the reaction with acid $\left(k_{\text {obs }}\right)$ and that without acid $\left(k_{0}\right)$ were determined to be 20 for $\mathrm{AcOH}, 70$ for DPP, 185 for $\mathrm{TsOH} \cdot \mathrm{H}_{2} \mathrm{O}, 4$ for $\mathrm{MsOH}$, and 215 for $\left(\mathrm{C}_{4} \mathrm{~F}_{9} \mathrm{SO}_{2}\right)_{2} \mathrm{NH}$. Although the highest value of $k_{\text {obs }} / k_{0}$ was obtained with $\left(\mathrm{C}_{4} \mathrm{~F}_{9} \mathrm{SO}_{2}\right)_{2} \mathrm{NH}$, it was not as high as expected from the difference in $\mathrm{p} K_{\mathrm{a}}$ values of $\left(\mathrm{C}_{4} \mathrm{~F}_{9} \mathrm{SO}_{2}\right)_{2} \mathrm{NH}$ and $\mathrm{TsOH} \cdot \mathrm{H}_{2} \mathrm{O}$ (see above). In addition, TsOH$\cdot \mathrm{H}_{2} \mathrm{O}$ is much less expensive than $\left(\mathrm{C}_{4} \mathrm{~F}_{9} \mathrm{SO}_{2}\right)_{2} \mathrm{NH}$ and it is readily available. Thus, we decided to optimise the reaction conditions for the present aerobic reduction catalysed by $\mathrm{TsOH} \cdot \mathrm{H}_{2} \mathrm{O}$.

A significant decrease in reactivity was observed when 1.1 equivalents of $\mathrm{NH}_{2} \mathrm{NH}_{2} \cdot \mathrm{H}_{2} \mathrm{O}$ were employed (Table S1, entries 1-3). Reducing the amount of $\mathrm{TsOH} \cdot \mathrm{H}_{2} \mathrm{O}$ to $2 \mathrm{~mol} \%$ led to lower efficiency, while increasing it to $10 \mathrm{~mol} \% \mathrm{did}$ not improve the reactivity appreciably (Table S1, entries 46 ). When the reaction was carried out under air, a white precipitate - presumably a hydrazonium salt of $\mathrm{TsOH}$ - was observed to form gradually, which could explain why a prolonged reaction time even with 3.5 equivalents of $\mathrm{NH}_{2} \mathrm{NH}_{2} \cdot \mathrm{H}_{2} \mathrm{O}$ was required to give $\mathbf{2 a}$ in a reasonable yield under such conditions (Table S1, entry 7). It should be noted that no reaction occurred under a nitrogen atmosphere (Table S1, entry 8). Further optimization of the reaction parameters showed acetonitrile to be the best solvent and $35^{\circ} \mathrm{C}$ to be the most suitable reaction temperature for efficient catalysis (Table S1, entries 9-17).

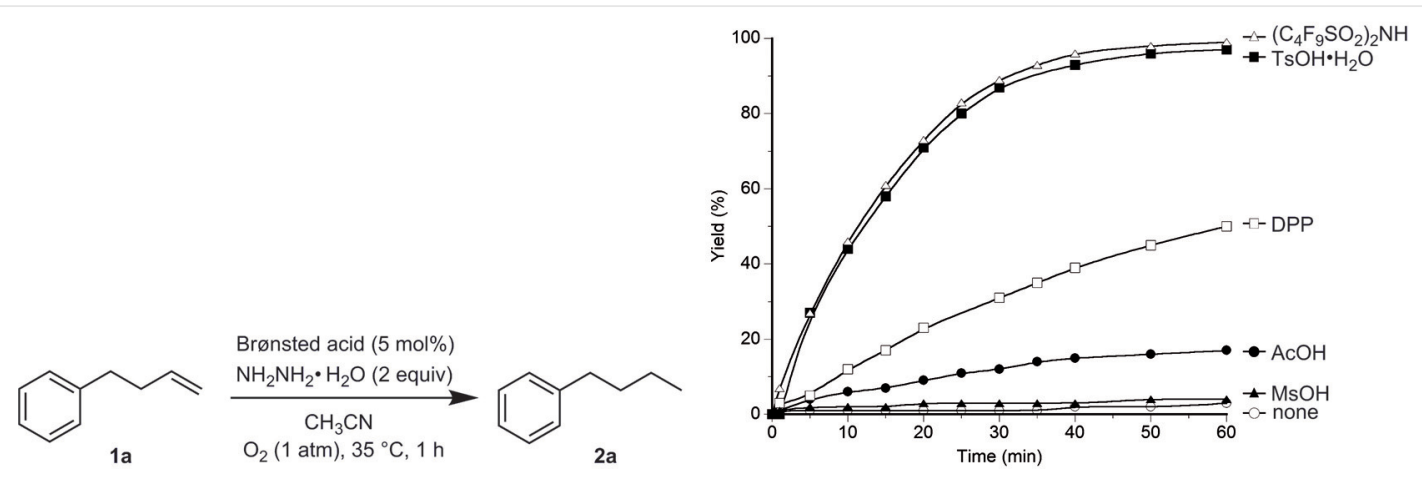

Scheme 2 Reaction profile of aerobic reduction of 1a with hydrazine with or without a Brønsted acid 
Table 1 Aerobic Reduction of Olefins Catalysed by $\mathrm{TsOH} \cdot \mathrm{H}_{2} \mathrm{O}^{\text {a }}$

(n)

${ }^{a}$ Reactions were performed using $1 \mathrm{mmol}$ of olefin, $2 \mathrm{mmol}$ of hydrazine monohydrate in $4 \mathrm{~mL}$ of acetonitrile in the presence of $5 \mathrm{~mol} \% \mathrm{TsOH} \cdot \mathrm{H}_{2} \mathrm{O}$ under $1 \mathrm{~atm}$ of $\mathrm{O}_{2}$ at $35^{\circ} \mathrm{C}$ and monitored by $\mathrm{GC}$ analysis.

b Time for full conversion.

' Isolated yield, unless otherwise noted.

${ }^{\mathrm{C}}$ Conversion determined by GC analysis.

e Determined by ${ }^{1} \mathrm{H}$ NMR measurement.

${ }^{\mathrm{f}}$ Conducted at $70^{\circ} \mathrm{C}$.
With the optimal reaction conditions in hand, we demonstrated the utility of the $\mathrm{TsOH}$-catalysed aerobic olefin reduction with hydrazine by applying the procedure to a range of substrates (Table 1). ${ }^{14}$ The reactions were performed on a $1 \mathrm{mmol}$ substrate scale and evaluated by GC analysis and/or isolated yields of hydrogenated products after full conversion of the substrates. Monosubstituted olefins 1a-k as well as disubstituted olefins 11-o could be efficiently reduced with excellent functional group tolerance. For instance, benzyl, epoxy, nitro, and azide groups, which are typically labile under metal-catalysed hydrogenation conditions, were unaffected by the reaction conditions (entries 5-8 and 14). There was also no adverse effect in the reduction of an olefin containing a sulfide functional group (entry 9), which often inhibits the catalytic activity of transition-metal complexes. The reduction of linalool $(\mathbf{1 j})$, bearing two carbon-carbon double bonds, afforded the monohydrogenated product $\mathbf{2} \mathbf{j}$ and the fully hydrogenated product in a ratio of 95:5, indicating the compatibility of the trisubstituted olefin as well as acid-labile tertiary alcohol group to the reaction conditions (entry 10). In addition, the present method can complement the aerobic hydrazine reduction catalysed by neutral flavins, because phenolic olefins such as $\boldsymbol{0}$-allylphenol (1k, entry 11$)$ are less reactive under flavin-related catalysis due to their acidic property reducing the reactivity of the basic hydrazine. ${ }^{8}$ Reduction of sterically more demanding $\alpha, \beta$ - as well as $\alpha, \alpha$-disubstituted olefins was also feasible without using extra hydrazine, although higher temperatures and prolonged reaction times were required for acyclic substrates $\mathbf{1 m}, \mathbf{1 n}$, and $\mathbf{1 0}$ (entries 13-15).

As initially envisaged, it is plausible that Brønsted acids accelerate the interconversion between trans- and cis-diimide and thereby facilitate the aerobic olefin reduction system. Although it could be expected that they would irreversibly form hydrazonium salts $\left({ }^{+} \mathrm{NH}_{3} \mathrm{NH}_{2}\right)$ and be deactivated, such an undesirable situation is apparently negligible as far as they are used under an atmosphere of $\mathrm{O}_{2}$ in acetonitrile, except in the case of $\mathrm{MsOH}$. For the representative catalysis with $\mathrm{TsOH} \cdot \mathrm{H}_{2} \mathrm{O}$, hydrazine can undergo reversible protonation to form ${ }^{2} \mathrm{NH}_{3} \mathrm{NH}_{2}$ as well as irreversible oxidation to form diimide (Scheme 3). Whereas the former is disfavoured in acetonitrile due to the low cation-solvation ability of this solvent, the latter is favoured because of the high oxygen-dissolving ability of acetonitrile. ${ }^{12}$ The present TsOH-catalysed aerobic olefin reduction was not accelerated under $365 \mathrm{~nm}$ UV light irradiation (entries 18 and 19, Table S1 in the Supporting Information), indicating that the equilibration of the isomeric diimides induced by $\mathrm{TsOH}$ is much faster than that induced by UV light irradiation as previously reported. ${ }^{6}$ 


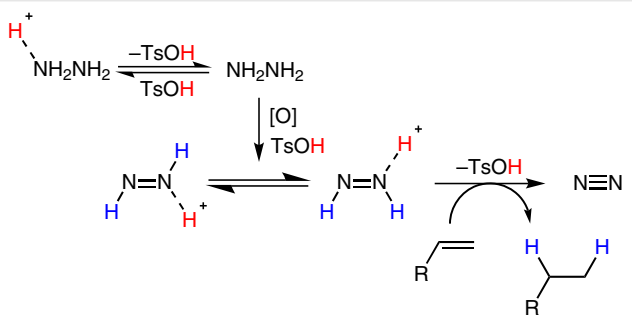

Scheme 3 Plausible reaction mechanism

In conclusion, we have introduced a new protocol for the aerobic reduction of olefins with hydrazine by using readily available Brønsted acids as catalysts. In particular, the use of $5 \mathrm{~mol} \% \mathrm{TsOH} \cdot \mathrm{H}_{2} \mathrm{O}$ and two equivalents of hydrazine monohydrate allowed a range of olefins to be reduced with excellent chemoselectivities under mild aerobic conditions. The present method is straightforward and should find wide application in organic synthesis. An asymmetric version of the protocol with chiral Brønsted acids ${ }^{15}$ is being explored in our laboratory.

\section{Acknowledgment}

This work was supported by a Grant-in-Aid for Scientific Research on Innovative Areas 'Advanced Molecular Transformations by Organocatalysts' from MEXT.

\section{Supporting Information}

Supporting information for this article is available online at http://dx.doi.org/10.1055/s-0036-1588790.

\section{References and Notes}

(1) Hanuš, J. Chem. Listy 1905, 29, 24.

(2) For reviews on aerobic reduction with diimide, see: (a) Pasto, D. J.; Taylor, R. T. Org. React. 1991, 40, 91. (b) Miller, C. E. J. Chem. Educ. 1965, 42, 254. (c) Hünig, S.; Müller, H. R.; Thier, W. Angew. Chem., Int. Ed. Engl. 1965, 4, 271.

(3) Chen, H.; Wang, J.; Hong, X.; Zhou, H.-B.; Dong, C. Can. J. Chem. 2012, 90, 758.

(4) Menges, N.; Balci, M. Synlett 2014, 25, 671.

(5) Lamani, M.; Guralamata, R. S.; Prabhu, K. R. Chem. Commun. 2012, 48, 6583.
(6) Leow, D.; Chen, Y.-H.; Hung, T.-H.; Su, Y.; Lin, Y.-Z. Eur. J. Org. Chem. 2014, 7347.

(7) Santra, S.; Guin, J. Eur. J. Org. Chem. 2015, 7253.

(8) (a) Imada, Y.; Iida, H.; Naota, T. J. Am. Chem. Soc. 2005, 127, 14544. (b) Imada, Y.; Kitagawa, T.; Ohno, T.; Iida, H.; Naota, T. Org. Lett. 2010, 12, 32. (c) Imada, Y.; Iida, H.; Kitagawa, T.; Naota, T. Chem. Eur. J. 2011, 17, 5908.

(9) (a) Smit, C.; Fraaije, M. W.; Minnaard, A. J. J. Org. Chem. 2008, 73, 9482. (b) Teichert, J. F.; den Hartog, T.; Hanstein, M.; Smit, C.; ter Horst, B.; Hernandez-Olmos, V.; Feringa, B. L.; Minnaard, A. J. ACS Catal. 2011, 1, 309. (c) Marsh, B. J.; Heath, E. L.; Carbery, D. R. Chem. Commun. 2011, 47, 280.

(10) (a) Pieber, B.; Martinez, S. T.; Cantillo, D.; Kappe, C. O. Angew. Chem. Int. Ed. 2013, 52, 10241. (b) Pieber, B.; Cox, D. P.; Kappe, C. O. Org. Process Res. Dev. 2016, 20, 376.

(11) Kleinke, A. S.; Jamison, T. F. Org. Lett. 2013, 15, 710.

(12) Koch, G. K. J. Labelled Compd. Radiopharm. 1969, 5, 99.

(13) For $\mathrm{p} K_{\mathrm{a}}$ values of Brønsted acids, see: (a) Kütt, A.; Leito, I.; Kaljurand, I.; Sooväli, L.; Vlasov, V. M.; Yagupolskii, L. M.; Koppel, I. A. J. Org. Chem. 2006, 71, 2829. (b) Dippy, J. F. J.; Hughes, S. R. C.; Rozanski, A. J. Chem. Soc. 1959, 2492. (c) Mutai, T.; Abe, Y.; Araki, K. J. Chem. Soc., Perkin Trans. 2 1997, 1805. (d) Izutsu, K. Electrochemistry in Nonaqueous Solvents; WileyVCH: Weinheim, 2002, Chap. 3. (e) Kütt, A.; Rodima, T.; Saame, E.; Raamat, E.; Mäemets, V.; Kaljurand, I.; Koppel, I. A.; Garlyauskayte, R. Y.; Yagupolskii, Y. L.; Yagupolskii, L. M.; Bernhardt, E.; Willner, H.; Leito, I. J. Org. Chem. 2011, 76, 391.

(14) A mixture of a solution of the olefin $(1.0 \mathrm{mmol})$ in acetonitrile $\left(2 \mathrm{~mL}\right.$ ) and a $0.05 \mathrm{M}$ stock solution of $\mathrm{TsOH} \cdot \mathrm{H}_{2} \mathrm{O}$ in acetonitrile ( $1 \mathrm{~mL}, 5 \mathrm{~mol} \%$ ) was stirred under an atmosphere of oxygen at 35 ${ }^{\circ} \mathrm{C}$ (for $\mathbf{1 a}-\mathbf{l}$ ) or $70{ }^{\circ} \mathrm{C}$ (for $\mathbf{1 m}-\mathbf{o}$ ) for $5 \mathrm{~min}$. To the resulting mixture was then added a solution of $\mathrm{NH}_{2} \mathrm{NH}_{2} \cdot \mathrm{H}_{2} \mathrm{O}(60 \mathrm{mg}, 1.2$ mmol) in acetonitrile $(1 \mathrm{~mL})$ and the mixture was further stirred at the corresponding temperature and monitored by GC analysis. After complete consumption of the olefin, the reaction was quenched with saturated aqueous $\mathrm{NaHCO}_{3}(3 \mathrm{~mL})$, and $\mathrm{Et}_{2} \mathrm{O}$ $(15 \mathrm{~mL})$ and $\mathrm{H}_{2} \mathrm{O}(7 \mathrm{~mL})$ were added. The aqueous layer was removed and the residual organic layer was washed with $\mathrm{H}_{2} \mathrm{O}(2$ $\times 10 \mathrm{~mL}$ ) and brine $(10 \mathrm{~mL})$, dried over $\mathrm{Na}_{2} \mathrm{SO}_{4}$, filtered, and concentrated under reduced pressure to give the corresponding hydrogenated product 2a-0. Data for butylbenzene (2a) [CAS Reg. No. 104-51-8]: yield: $127 \mathrm{mg}(92 \%) .{ }^{1} \mathrm{H}$ NMR (400 MHz, $\left.\mathrm{CDCl}_{3}, 25^{\circ} \mathrm{C}\right): \delta=0.92\left(\mathrm{t}, J=7.3 \mathrm{~Hz}, 3 \mathrm{H}, \mathrm{CH}_{3}\right), 1.30-1.42(\mathrm{~m}, 2 \mathrm{H}$, $\left.\mathrm{CH}_{2}\right), 1.55-1.65\left(\mathrm{~m}, 2 \mathrm{H}, \mathrm{CH}_{2}\right), 2.61\left(\mathrm{t}, J=7.8 \mathrm{~Hz}, 2 \mathrm{H}, \mathrm{ArCH}_{2}\right)$, 7.12-7.31 (m, $5 \mathrm{H}, \mathrm{ArH}) .{ }^{13} \mathrm{C}$ NMR $\left(100 \mathrm{MHz}, \mathrm{CDCl}_{3}, 25{ }^{\circ} \mathrm{C}\right): \delta=$ 13.9, 22.4, 33.7, 35.7, 125.5, 128.2, 128.4, 142.9. MS (EI): $m / z(\%)$ $=134(26)\left[\mathrm{M}^{+}\right], 105(8)\left[\mathrm{C}_{6} \mathrm{H}_{5} \mathrm{CH}_{2} \mathrm{CH}_{2}\right], 91(100)\left[\mathrm{C}_{6} \mathrm{H}_{5} \mathrm{CH}_{2}\right], 77$ (6) $\left[\mathrm{C}_{6} \mathrm{H}_{5}\right], 65(16)\left[\mathrm{C}_{5} \mathrm{H}_{5}\right], 51(11)\left[\mathrm{C}_{4} \mathrm{H}_{3}\right], 39(18)\left[\mathrm{C}_{3} \mathrm{H}_{3}\right]$

(15) For reviews on chiral Brønsted acid catalysis, see: (a) Akiyama, T.; Mori, K. Chem. Rev. 2015, 115, 9277. (b) Parmar, D.; Sugiono, E.; Raja, S.; Rueping, M. Chem. Rev. 2014, 114, 9047. (c) Akiyama, T. Chem. Rev. 2007, 107, 5744. 